\title{
Dental injuries in taekwondo athletes practicing in Saudi Arabia
}

\author{
Yazan R. Aljohani, BDS, Khalid H. Alfaif, BDS, Samaa K. Redwan, BDS, Dania A. Sabbahi, BDS, PhD, \\ Mohammed H. Zahran, BDS, PhD.
}

\begin{abstract}
الأهدف: التحقق من مدى تعرض لاعبي رياضة التايكوندو

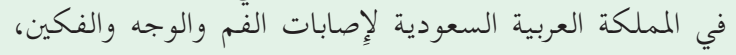
ووعيهم بها وكيفيه الوقاية منها.

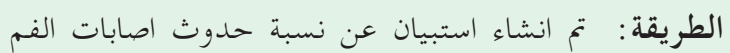

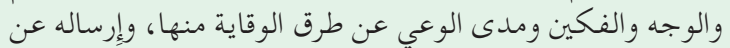

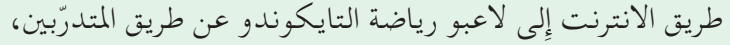

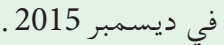

النتائج : تم تعبئة 68 استبيان فقط . كان متوسط أعمار المشاركين

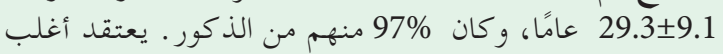

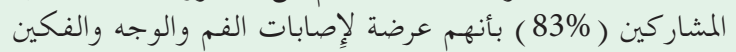

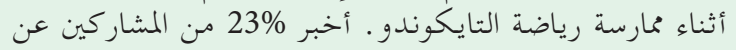

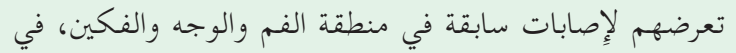

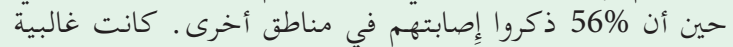

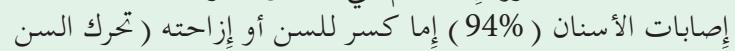

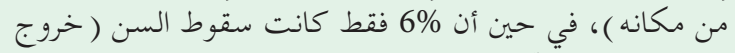

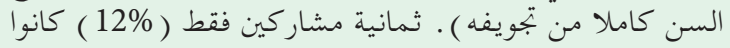

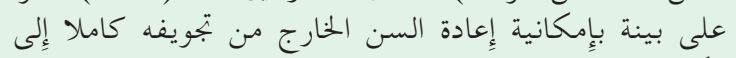

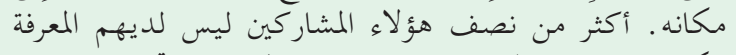

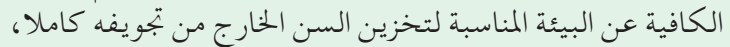

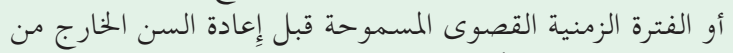

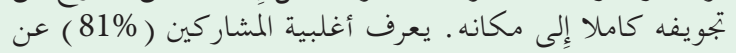

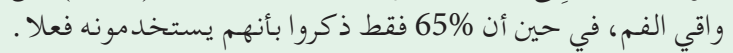

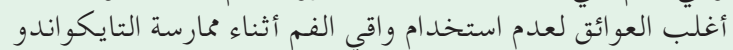

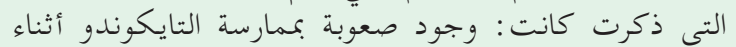

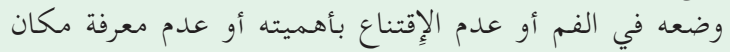

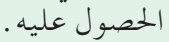

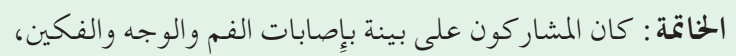

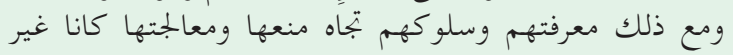
كافيين.

Objectives: To assess the incidence and awareness of taekwondo athletes in Saudi Arabia regarding oral and maxillofacial (OMF) injuries and their prevention.
Methods: In this cross-sectional study, an online questionnaire about the incidence and awareness of OMF injuries and their prevention was developed and distributed to taekwondo athletes in Saudi Arabia via their coaches.

Results: Sixty-eight responses were collected. The mean age of the participants was $29.3 \pm 9.1$ years and $97 \%$ of them were males. Most of the participants $(83 \%)$ believed that they are vulnerable to OMF injuries during practice. Approximately $23 \%$ of the participants reported a previous injury of the OMF area, while approximately 56\% reported injuries in other areas. Most dental injuries (94\%) were tooth fracture or displacement, while $6 \%$ were tooth avulsion. Eight participants (12\%) were aware of the possibility of returning an avulsed tooth to its socket. More than $50 \%$ of those participants had inadequate knowledge on the appropriate storage media for the avulsed tooth or the maximum time allowed to return it to its socket. Eighty-one percent of the participants knew about the mouthguard, while 56\% reported that they are actually using one. The most frequently reported barriers for not using a mouthguard during practice were difficulty in practicing with it, not being convinced of its importance, and lack of information where to get one.

Conclusions: Most of the participants are aware of OMF injuries; however, their knowledge and behavior towards preventing and managing them are inadequate.

Saudi Med J 2017; Vol. 38 (11): 1143-1147 doi: 10.15537/smj.2017.11.21111

From the Department of Dental Public Health (Sabbahi), the Department of Oral and Maxillofacial Prosthodontics (Zahran), Faculty of Dentistry (Aljohani, Alfaifi, Redwan), King Abdulaziz University, Jeddah, Kingdom of Saudi Arabia.

Received 10th July 2017. Accepted 9th August 2017.

Address correspondence and reprint request to: Dr. Dania A. Sabbahi, Department of Dental Public Health, Faculty of Dentistry King Abdulaziz University, Jeddah, Kingdom of Saudi Arabia. E-mail:dsabbahi@kau.edu.sa 
$\mathrm{T}$ aekwondo is an international martial arts sport with a heavy emphasis on head-height, fast, jumping, and spinning kicks. Taekwondo athletes are 3 times more at risk of orofacial injuries than non-contact sports practitioners, ${ }^{1}$ with an incidence of orofacial injuries ranging between $20-34 \% .^{2,3}$ In 2001, the World Taekwondo Federation (WTF) introduced a new scoring system that awards more points for kicks to the head. ${ }^{1}$ This scoring system led to an increase in orofacial injuries. ${ }^{4}$ Orofacial injuries include soft tissue laceration, bone fractures, and teeth fractures. ${ }^{5}$ Prevention is the best approach to such injuries since treatment can be complicated and expensive. According to the American Dental Association, a properly fitted mouthguard is the best protective device for reducing the incidence and severity of sports-related dental injuries. ${ }^{6,7}$ A custom mouthguard made for an athlete by a dentist offers the best protection from dental injuries; however, it can be costly. Other types of mouthguard found in sports stores for low prices, including boil-and-bite and stock mouthguards, are not recommended since they offer less protection and comfort and might dislodge during use and obstruct the airway. ${ }^{8}$

A study by Vidovic et $\mathrm{al}^{9}$ evaluated the incidence of dental and facial injuries, the habits and awareness regarding wearing a mouthguard, and awareness regarding prevention and management of tooth avulsion. In a survey conducted on 484 taekwondo athletes during national championships or tournaments, 96\% of the participants wore mouthguards but only 5\% used custom-made ones and among all participants, $62 \%$ had sustained a serious injury. A study by Lee et $\mathrm{al}^{1}$ assessed the level of mouthguard use, attitude, awareness, and wearability issues among elite Korean taekwondo athletes. Although the provision of information on mouthguard was found to be inadequate, the majority of respondents consider mouthguard an effective prevention device against injuries. Another study was conducted by Kececi et $\mathrm{al}^{10}$ on 162 athletes; of those athletes, 52 were taekwondo athletes. They found that $24 \%$ of the taekwondo athletes suffered at least one type of dental injury and only $10 \%$ wore a mouthguard.

The aim of this study to was investigate the incidence of dental and facial injuries amongst taekwondo athletes in Saudi Arabia and their awareness regarding their prevention and management.

Disclosure. Authors have no conflict of interests, and the work was not supported or funded by any drug company.
Methods. A questionnaire was developed, based on previous studies, ${ }^{911-13}$ in December 2015, to survey taekwondo players about the incidence and awareness in regards to oral and maxillofacial (OMF) injuries and their prevention and management. The questionnaire was in Arabic and consisted of 4 sections. The first section contained 5 questions and queried the participants about their demographic information. The second section contained 4 questions and queried the participants about their knowledge and experience with injuries including OMF injuries. The third section contained 5 questions and queried the participants about their knowledge and experience with the management of OMF injuries. The fourth section contained five questions and queried the participants about their knowledge, behavior, and attitude in regards to mouthguards.

An ethical approval was obtained from the Ethical Committee at King Abdulaziz University, Faculty of Dentistry (KAUFD) and all procedures performed were in accordance with the 1964 Helsinki Declaration and its later amendments or comparable ethical standards. The targeted population was semi-professional and amateur taekwondo athletes in the 5 most populated regions of Saudi Arabia. The questionnaire and consent were made using Google Docs (Google Inc., Googleplex, Mountain View, California, USA) and distributed to the coaches in the Saudi Taekwondo Coaches Network using the instant messaging software WhatsApp (WhatsApp Inc., Mountain View, California, USA). All participants consented electronically before filling the online questionnaire.

Statistical analysis. Data was collected, tabulated, and statistically analyzed to estimate descriptive statistics (frequencies, percentages, means, and accompanying standard deviations or $95 \%$ confidence intervals where appropriate). All statistical analyses were conducted using SPSS (version 16.0, SPSS Inc., Chicago, IL, USA).

Results. The questionnaire was distributed to 396 athletes. Sixty-eight responses were collected (response rate: 17\%). The mean age of the participants was $29.3 \pm 9.1$ years and about $97 \%$ of them were male. Most of the participants believed that they are vulnerable to oral and maxillofacial (OMF) injuries during practice and recognized the importance of early intervention after injury, $83 \%$ and $90 \%$, respectively (Table 1). Approximately $23 \%$ of the participants reported a previous injury of OMF area (more than half of them did not seek any treatment after injury), while 
about $56 \%$ reported injuries in other areas (Table 2). The majority of the dental injuries (94\%) were tooth fracture or displacement, while only $6 \%$ were tooth avulsion (Table 3). Only 8 participants (12\%) were aware of the possibility of returning an avulsed tooth to its socket (Table 4). More than half of those participants had inadequate knowledge about the appropriate storage media for the avulsed tooth or the maximum time allowed to return the avulsed tooth to its socket (Table 5). Majority of the participants (81\%) knew about the mouthguard, while only $56 \%$ reported that they use one. The most frequently reported barriers to

Table 1 - Responses as to the possibility of oral and maxillofacial injury and the importance of early intervention.

\begin{tabular}{lccc}
\hline Responses & No & Yes & I don't know \\
\hline $\begin{array}{l}\text { Do you think that oral and } \\
\text { maxillofacial injuries can } \\
\text { occur during taekwondo } \\
\text { practice? }\end{array}$ & $6(8.8)$ & $57(83.8)$ & $5(7.4)$ \\
$\begin{array}{l}\text { Do you think that immediate } \\
\text { management of dental } \\
\text { injuries by a dentist is very } \\
\text { important to increase the rate } \\
\text { of treatment success? }\end{array}$ & $2(2.9)$ & $61(89.7)$ & $5(7.4)$ \\
\hline \multicolumn{1}{c}{ Values are expressed as number and percentage (\%) } \\
\hline
\end{tabular}

Table 2 - Responses as to previous oral and maxillofacial trauma and if they seek treatment after trauma

\begin{tabular}{lc}
\hline Responses & $\mathbf{n}(\%)$ \\
\hline $\begin{array}{l}\text { Do you have any experience of oral and maxillofacial } \\
\text { trauma during taekwondo practice? }\end{array}$ \\
$\quad$ No & $45(66.2)$ \\
Yes & $16(23.5)$ \\
I don't remember & $7(10.3)$ \\
If you suffered a dental trauma, where did you go? & \\
Hospital emergency & $2(12.5)$ \\
Dentist (private sector) & $5(31.3)$ \\
I didn't go to any doctor & $9(56.2)$ \\
\hline
\end{tabular}

Table 3 - Responses as to the type of dental injury.

\begin{tabular}{lc}
\hline Responses & $\mathbf{n ~ ( \% )}$ \\
\hline What kind of dental trauma did you experience? & $1(6.2)$ \\
Tooth avulsion & $7(43.8)$ \\
Tooth displacement & $8(50.0)$ \\
Tooth fracture & \\
\hline
\end{tabular}

using a mouthguard during practice were difficulty in practicing with it, not being convinced of its importance and lack of knowledge of where to get one (Table 6).

Discussion. The use of mouthguard has been mandatory in local and international taekwondo tournaments; however, there have not been any studies in regard to mouthguard use amongst taekwondo athletes in Saudi Arabia. ${ }^{1}$

In this study, the majority of the participants believed that they are vulnerable to OMF injuries and knew about mouthguards $83 \%$ and $81 \%$, respectively;

Table 4 - Responses as to the possibility of returning an avulsed tooth to its socket.

\begin{tabular}{lr}
\hline Responses & $\mathbf{n ~ ( \% )}$ \\
\hline $\begin{array}{l}\text { Do you think that it is possible to put the tooth back } \\
\text { in its original socket? }\end{array}$ \\
No & $25(36.7)$ \\
Yes & $8(11.8)$ \\
I don't know & $35(51.5)$ \\
\hline
\end{tabular}

Table 5 - Responses as to the appropriate storage media for the avulsed tooth/the maximum time allowed to return the avulsed tooth its socket.

\begin{tabular}{lc}
\hline Responses & $\mathbf{n}(\%)$ \\
\hline What is the right way to store an avulsed tooth while going to the \\
dentist? \\
Store the tooth in a solution & $4(50)$ \\
Store the tooth in a gauze & $2(25)$ \\
I don't know & $2(25)$ \\
What is the maximum time for a tooth to be out of the mouth before \\
being put back in its socket? \\
Within 1 hour \\
12 hours & $2(25)$ \\
One day & $1(12.5)$ \\
I don't know & $2(25.0)$ \\
\hline
\end{tabular}

Table 6 - Responses on the barriers for using a mouthguard during practice.

\begin{tabular}{lc}
\hline Responses & $\mathbf{n ~ ( \% )}$ \\
\hline Barriers for using a mouthguard during practice & \\
Difficulty in practicing & $9(29.0)$ \\
Not convinced of its importance & $12(38.7)$ \\
Lack of information on where to get one & $10(32.3)$ \\
\hline
\end{tabular}


however, only $56 \%$ reported wearing one which is comparable to the findings of Lee et al. in a study of elite Korean taekwondo athletes in 2013 in which 56\% reported not having experience with mouthguards. ${ }^{1}$

One of the most frequently reported barriers to wearing a mouthguard is difficulty during practice while wearing one (29\%); this was also reported in other studies. ${ }^{1,9,11,14-18}$ This can be attributed to the type of mouthguard used as none of the participants in this study wore custom-made mouthguards. According to previous studies, $7,10,12,14,18,19$ the use of non-custommade mouthguards (stock or boil-and-bite), unlike custom-made ones, causes breathing problems. Although non-custom-made mouthguards are cheaper and easier to acquire, they might also cause difficulty in talking," jaw muscle fatigue, dislodge during use and obstruct the airway. ${ }^{1,8,9}$ For that, many studies recommended the usage of a custom-made mouthguard. ${ }^{20-23}$ Another reported barrier to wearing mouthguards is not being convinced of its importance (39\%), which is consistent with similar studies. ${ }^{12,13}$ Interestingly, in a study by Spinas and Savasta, ${ }^{24}$ only $1 \%$ of the participants wore a mouthguard, and after having suffered a dental injury all of them started wearing one. Awareness about mouthguard is significantly influenced by the coaches; as a matter of fact, $81 \%$ of the participants knew about the mouthguard and $56 \%$ of those knew about it from their coaches. ${ }^{9,25}$ Dental professionals have an important role in promoting wearing custom-made mouthguards since many of the participants reported a lack of information on how to get a mouthguard as a barrier to wearing one $(32 \%){ }^{11-13,18}$ Also, none of the participants in this study wore a custom-made mouthguard and those who wore non-custom-made mouthguards complained of difficulties in wearing them.

Most participants (90\%) recognized the importance of early intervention after injury. About $23 \%$ of the participants in this study experienced OMF injuries, which is similar to previous studies, ${ }^{9,11,18,26}$ half of which did not seek any treatment after the injury, a finding which was also reported by approximately fifth $(23 \%)$ of the participants in a study by Rouhani et $\mathrm{al}^{18}$ on Iranian contact sports athletes. Most OMF injuries (94\%) were tooth fracture or displacement, similar to previous studies, ${ }^{10,26}$ and $6 \%$ were tooth avulsion. Most of these injuries can be easily avoided and treated and for that an emphasis on having an interaction between the dental community and the sports community is vital as it will improve the athletes' compliance and knowledge.

Many previous studies ${ }^{9,13,15,27}$ reported low knowledge in regards to the possibility of returning an avulsed tooth to its socket and how to store an avulsed tooth. In a study by Vidovic et $\mathrm{al}^{9}$ on Croatian taekwondo athletes, $44 \%$ of athletes knew about the possibility of returning an avulsed tooth while, surprisingly, in our study only $12 \%$ were aware of the possibility of returning an avulsed tooth to its socket and only $25 \%$ had adequate knowledge about the appropriate storage media for the avulsed tooth or the maximum time allowed to return the avulsed tooth its socket. This is an alarming finding that, again, urges the dental community to have a continuous interaction with the sports community.

The response rate in this study was low, which can be attributed to the lack of individual follow-up due to the fact that participants were not approached individually but through their coaches. This low response rate will not likely affect the study recommendation for a better role for the dental community in educating the sports community about OMF injuries, and their management and prevention.

In conclusion, the results of our study show that the incidence of OMF injuries in taekwondo athletes practicing in Saudi Arabia is similar to that in other countries. The awareness about such injuries was high; however, knowledge and proper behavior in regards to their prevention and management are alarmingly inadequate since the majority lacked information on managing such injuries and almost half the injured did not seek treatment after the injury. As for prevention, none of the participants wore a custom-made mouthguard; many reported not being convinced of its importance, and many lacked the information of where to get one.

\section{References}

1. Lee JW, Heo CK, Kim SJ, Kim GT, Lee DW. Mouthguard use in Korean Taekwondo athletes - awareness and attitude. $J A d v$ Prosthodont 2013; 5: 147-152.

2. Pieter W, Fife GP, O'Sullivan DM. Competition injuries in taekwondo: a literature review and suggestions for prevention and surveillance. Br J Sports Med 2012; 46: 485-491.

3. Pieter W. Martial arts injuries. Med Sport Sci 2005; 48: 59-73.

4. Kim GH, Lee JP, Kim HS, Jung HJ, Oh JK. The clinical comparison of injury pattern before and after rule revision in Taekwondo. J Korea Sport Res 2007; 18: 619-629.

5. Siana JE, Borum P, Kryger H. Injuries in Taekwondo. Br J Sports Med 1986; 20: 165-166.

6. ADA Council on Access, Prevention and Interprofessional Relations; ADA Council on Scientific Affairs. Using mouthguards to reduce the incidence and severity of sportsrelated oral injuries. J Am Dent Assoc 2006; 137: 1712-1720.

7. Levin L, Zadik Y. Education on and prevention of dental trauma: It's time to act! Dent Traumatol 2012; 28: 49-54. 
8. Jagger RG. Mouthguards. Br Dent J 1996; 180: 50.

9. Vidovic D, Bursac D, Skrinjaric T, Glavina D, Gorseta K. Prevalence and prevention of dental injuries in young taekwondo athletes in Croatia. Eur J Paediatr Dent 2015; 16: 107-110.

10. Keçeci AD, Eroglu E, Baydar ML. Dental trauma incidence and mouthguard use in elite athletes in Turkey. Dent Traumatol 2005; 21: 76-79.

11. Ferrari CH, Ferreria de Mederios JM. Dental trauma and level of information: Mouthguard use in different contact sports. Dent Traumatol 2002; 18: 144-147.

12. Biagi R, Cardarelli F, Butti AC, Salvato A. Sports-related dental injuries: Knowledge of first aid and mouthguard use in a sample of Italian children and youngsters. Eur J Paediatr Dent 2010; 11: 66-70.

13. Perunski S, Lang B, Pohl Y, Filippi A. Level of information concerning dental injuries and their prevention in Swiss basketball - A survey among players and coaches. Dent Traumatol 2005; 21: 195-200.

14. Gardiner DM, Ranalli DN. Attitudinal factors influencing mouthguard utilization. Dent Clin North Am 2000; 44: 53-65.

15. Correa MB, Schuch HS, Collares K, Torriani DD, Hallal PC, Demarco FF. Survey on the occurrence of dental trauma and preventive strategies among Brazilian professional soccer players. J Appl Oral Sci 2010; 18: 572-576.

16. Abella F, Patel S, Duran-Sindreu F, Mercadé M, Bueno R, Roig M. Evaluating the periapical status of teeth with irreversible pulpitis by using cone-beam computed tomography scanning and periapical radiographs. J Endod 2012; 38: 1588-1591.

17. Johnsen DC, Winters JE. Prevention of intraoral trauma in sports. Dent Clin North Am 1991; 35: 657-666.
18. Rouhani A, Ghoddusi J, Rahmandost M, Akbari, M. Prevalence of traumatic dental injuries among contact sport practitioners in Northeast of Iran in 2012. Journal of Dental Materials and Techniques 2016; 5: 82-85.

19. Von Arx T, Flury R, Tschan J, Buergin W, Geiser T. Exercise capacity in athletes with mouthguards. Int J Sports Med 2008; 29: 435-438.

20. Cetin C, Keçeci AD, Erdoğan A, Baydar ML. Influence of custom-made mouth guards on strength, speed and anaerobic performance of taekwondo athletes. Dent Traumatol 2009; 25: 272-276.

21. Yamada T, Sawaki Y, Tomida S, Tohnai I, Ueda M. Oral injury and mouthguard usage by athletes in Japan. Endod Dent Traumatol 1998; 14: 84-87.

22. Scott J, Burke FJ, Watts DC. A review of dental injuries and the use of mouthguards in contact team sports. Br Dent J 1994; 176: 310-314.

23. Newsome PR, Tran DC, Cooke MS. The role of the mouthguard in the prevention of sports-related dental injuries: A review. Int J Paediatr Dent 2016; 11: 396-404.

24. Spinas E, Savasta A. Prevention of traumatic dental lesions: Cognitive research on the role of mouthguards during sport activities in paediatric age. Eur J Paediatr Dent 2007; 8: 193-198.

25. Azodo CC, Odai CD, Osazuwa-Peters N, Obuekwe ON. A survey of orofacial injuries among basketball players. Int Dent J 2016; 61: 43-46.

26. Mori GG, de Mendonça Janjácomo DM, Castilho LR, Poi WR. Evaluating the knowledge of sports participants regarding dental emergency procedures. Dent Traumatol 2009; 25: 305-308.

27. Fakhruddin KS, Lawrence HP, Kenny DJ, Locker D. Use of mouthguards among 12- to 14-year-old Ontario schoolchildren. J Can Dent Assoc 2016; 73: 505. 